\title{
The Presence of Background Dopamine Signal Converts Long-Term Synaptic Depression to Potentiation in Rat Prefrontal Cortex
}

\author{
Yoshiki Matsuda, Aude Marzo, and Satoru Otani \\ Laboratory of Neuromodulation, Neuronal Plasticity and Cognition, Centre National de la Recherche Scientifique-Unité Mixte de Recherche 7102 \\ Neurobiologie des Processus Adaptatifs, Université Paris VI Pierre et Marie Curie, 75005 Paris, France
}

\begin{abstract}
Executive functions of the brain are believed to require tonic dopamine inputs to the prefrontal cortex (PFC). It is unclear, however, how this background dopamine activity controls synaptic plasticity in the PFC, a possible underlying mechanism of executive functions. Using PFC slices, we show that pairing of dopamine with weak tetanic stimulation, a maneuver that otherwise induces NMDA receptorindependent long-term depression (LTD), induces long-term potentiation (LTP) when "primed" with dopamine. This "priming" occurs through the combined activation of $\mathrm{D}_{1}$ and $\mathrm{D}_{2}$ receptors and requires $12-40 \mathrm{~min}$ to develop. Moreover, concurrent synaptic activation of NMDA receptors during priming is necessary for this novel form of LTP. We suggest that a role of background dopamine signals in the PFC is to prevent high-frequency synaptic inputs from abnormally inducing LTD and to secure the induction of LTP.
\end{abstract}

Key words: long-term potentiation; long-term depression; dopamine; prefrontal cortex; priming; NMDA receptor

\section{Introduction}

Midbrain dopamine neurons exhibit fast phasic and "background" tonic activities (Grace, 1991; Schultz, 2002). The phasic activity is thought to be involved in the encoding of rewardrelated signals (Reynolds et al., 2001; Schultz, 2002) and promotes long-term potentiation (LTP) in the striatum (Reynolds et al., 2001), hippocampus (Frey et al., 1991), and prefrontal cortex (PFC) (Gurden et al., 1999; Huang et al., 2004). The slow tonic activity supplies ambient concentrations of dopamine in target areas (Floresco et al., 2003), including the PFC (Bassareo and Di Chiara, 1997; Takahata and Moghaddam, 2000). This background presence of dopamine is thought to provide crucial control over higher cognitive functions mediated by the PFC (Akil et al., 1999; Schultz, 1998, 2002).

Lines of animal studies indeed show that manipulations of dopaminergic tone either by direct infusion of dopamine agonists/antagonists in the PFC (Sawaguchi and Goldman-Rakic, 1991; Zahrt et al., 1997; Baldwin et al., 2002; Wang et al., 2004) or by a lesion of ventral tegmental area (Simon et al., 1980) cause significant alterations in executive functions. It is generally thought that the background dopamine level regulates the sensitivity of PFC neurons to event-related inputs (Williams and Goldman-Rakic, 1995). To date, however, the specific cellular

\footnotetext{
Received Dec. 13, 2005; revised March 25, 2006; accepted March 25, 2006.

This work was supported by the French Minister of Research, the Centre National de la Recherche Scientifique, and the University of Paris VI. We are grateful to Drs. Bai Lu, Cliff Abraham, Yukiori Goto, Bogdan Kolomiets, Therese Cronin, Tim Bliss, John Lisman, David Lewis, Julie Frey, and Matthijs Feenstra for their useful comments.

Correspondence should be addressed to Satoru Otani at the above address. E-mail: satoru.otani@snv.jussieu.fr.

D0I:10.1523/JNEUROSCI.5312-05.2006

Copyright $\odot 2006$ Society for Neuroscience $\quad 0270-6474 / 06 / 264803-08 \$ 15.00 / 0$
}

mechanisms underlying the effect of tonic background dopamine level on executive functions are still unknown.

An emerging view is that the executive functions depend on lasting neuronal traces formed and stored within the PFC (Dias and Aggleton, 2000; Fuster et al., 2000; Rossi et al., 2001; Simons and Spiers, 2003; Runyan et al., 2004) and that synaptic plasticity in the PFC serves as a mechanistic basis for these neuronal traces (Laroche et al., 2000). Indeed, lasting alterations in discharge rate of PFC neurons were detected during the acquisition of operant spatial discrimination task (Mulder et al., 2003). Furthermore, long-term changes of PFC synaptic transmission were found to accompany a form of behavioral adaptation (Herry and Garcia, 2002).

Here, we hypothesize that tonic background dopamine activity plays a key role in the regulation of PFC synaptic plasticity. Given that dopaminergic projection is removed, the acute PFC slices serve as an excellent model system, which allowed us to mimic background dopaminergic inputs by a "priming" bathapplication of dopamine. Previously, we showed that paring tetanic stimulation to bath-application of dopamine (100 $\mu \mathrm{M} ; 12.5$ min) induces long-term depression (LTD) (Otani et al., 1998, 1999). In the present study, to compare with this protocol and to isolate the background stimulation phase, we performed a dopamine double-application protocol. In this protocol, dopamine was applied alone (100 $\mu \mathrm{M} ; 12.5 \mathrm{~min}) 40 \mathrm{~min}$ before the delivery of the dopamine-tetanic stimulation paring. In the second series of experiments, to supply background dopamine in a more physiologically relevant manner, we continuously applied a lower concentration of dopamine $(3 \mu \mathrm{M})$ before the pairing. In both cases, surprisingly, the priming of dopamine receptors converted the LTD to LTP. 


\section{Materials and Methods}

Slice preparation. All experiments were conducted in accordance with the Policies on the Use of Animals in Neuroscience as approved by the Society for Neuroscience. Male Sprague Dawley rats (23-30 d of age) were decapitated, and their brains were rapidly removed from their skull. Coronal slices containing the prelimbic area of medial frontal cortex (300 $\mu \mathrm{m} ; 2.2-3.7 \mathrm{~mm}$ from the bregma) were sectioned by the use of a Campden vibratome (Campden Instruments, Leics, UK) in chilled $\left(\sim 0^{\circ} \mathrm{C}\right)$ oxygenated $\left(95 \% \mathrm{O}_{2} / 5 \% \mathrm{CO}_{2}\right)$ artificial CSF (ACSF) composed of the following (in mM): $124 \mathrm{NaCl}, 2 \mathrm{KCl}, 26 \mathrm{NaHCO}_{3}, 1.15 \mathrm{KH}_{2} \mathrm{PO}_{4}, 1 \mathrm{MgCl}_{2}$, $2 \mathrm{CaCl}_{2}$, and $11 \mathrm{D}$-glucose. The slices were allowed to recover for at least $3 \mathrm{~h}$ at room temperature $\left(\sim 20^{\circ} \mathrm{C}\right)$ in continuously oxygenated ACSF. The slices were transferred, one at a time, to a submersion-type recording chamber and perfused with warmed $\operatorname{ACSF}\left(28^{\circ} \mathrm{C}\right)$ at the rate of $1 \mathrm{ml} / \mathrm{min}$.

By the use of sharp glass micropipettes (GC120F-10; Harvard Apparatus, Holliston, MA) filled with $3 \mathrm{M} \mathrm{K}$-acetate (80-120 M $\Omega$ tip resistance), the soma of $>170$ layer $V$ pyramidal neurons in the prelimbic area was penetrated. Negative currents were initially injected with an Axoclamp 2A amplifier (Molecular Devices, Union City, CA) or a BVC-700A amplifier (Dagan Corporation, Minneapolis, MN). After stabilization of the cells, all or most currents were removed. On average, the cells had a resting membrane potential of $-71 \pm 0.5 \mathrm{mV}$, and the potential during the experiments was maintained at $-74 \pm 0.4 \mathrm{mV}$. Cells that had a resting membrane potential more negative than $-60 \mathrm{mV}$, a spike height of $60 \mathrm{mV}$ or larger, and an initial input resistance of $30 \mathrm{M} \Omega$ or larger were considered healthy. The spike height and the input resistance were reexamined at the end of the experiments. Furthermore, input resistance and bridge balance were often tested during the course of the experiments, with spike height also retested when necessary. Experiments were terminated in cases where cells showed a sign of deterioration (i.e., a constant decline in any of the aforementioned parameters such that $>10 \%$ deviations from initial values were observed). On average, initial and final spike heights of the accepted cells were $71 \pm 0.5$ and $70 \pm 0.6$ $\mathrm{mV}$, respectively. Initial and final input resistances were $54 \pm 1.2$ and $55 \pm 1.3 \mathrm{M} \Omega$, respectively.

Before the experiments, spike discharge mode was routinely examined by applying a depolarizing current step $(500 \mathrm{~ms})$ from resting membrane potential. The intensity of the depolarizing step was set at the level where a $30 \mathrm{~ms}$ application of the step produced one action potential. Sixty-two percent of the cells were classified as regular spiking, $13 \%$ as bursting, and $25 \%$ as "adaptation cells" in which initial repetitive spikes ceased abruptly with a strong adaptation. There were no correlations between a discharge mode and the other measurements, including the degree of synaptic plasticity.

Stimulation, recording, and data analysis. A bipolar Teflon-coated tungsten stimulating electrode (external diameter, $125 \mu \mathrm{m}$; A-M Systems, Carlsborg, WA) was placed on layer I-II of the prelimbic area (immediately interior to the pial surface). The EPSP of $\sim 10 \mathrm{mV}$ in amplitude was evoked at $0.033 \mathrm{~Hz}$ by the application of monophasic constant current square pulses (100 $\mu$ s duration; A360 stimulus isolator; World Precision Instruments, Sarasota, FL). After acquisition of the baseline responses for a period of at least $20 \mathrm{~min}$, drug application was initiated. All drugs were included in perfusing medium. In a given set of experimental conditions (e.g., those involving the dopamine receptor antagonists), the experiments were always performed in an interleaved manner. To induce long-term plasticity, a train of tetanic stimuli (100 pulses applied at $50 \mathrm{~Hz}$ ) was delivered four times at $0.1 \mathrm{~Hz}$. All evoked responses were fed to an Axoclamp 2A or BVC-700A amplifier in current-clamp mode and digitized at $10 \mathrm{kHz}$ through a Digidata $1322 \mathrm{~A}$ interface (Molecular Devices) by the use of Elphy data acquisition program (developed by Dr. G. Sadoc, Institut Alfred Fessard, Centre National de la Recherche Scientifique, Gif-sur-Yvette, France). Individual responses and the changes in the EPSP slope were monitored on-line, whereas the detailed data analysis was performed off-line.

For the analysis, the initial rising slope of the EPSP ( $1 \mathrm{~ms}$ period from its onset, $\mathrm{mV} / \mathrm{ms}$ ), which contains only a monosynaptic component (Hirsch and Crepel, 1990), was calculated for each individual EPSP evoked by the $0.033 \mathrm{~Hz}$ test pulses. Changes of the EPSP slope after conditioning/drug application (35-45 min period after conditioning, denoted as "40 min after conditioning") were expressed as a percentage increase or decrease from the preconditioning baseline level (the $10 \mathrm{~min}$ period just before tetanic stimulation or drug application). The percentage values obtained were compared between different experimental groups.

All experiments were performed in the presence of the $\mathrm{GABA}_{\mathrm{A}}$ antagonist bicuculline methiodide $(1 \mu \mathrm{M})$. The presence of bicuculline did not disrupt the EPSP for at least $2 \mathrm{~h}$ of recording. Percentage changes of the EPSP slope 60 and $120 \mathrm{~min}$ after the beginning of bicuculline perfusion were $4.6 \pm 7.3$ and $-2.1 \pm 6.9 \%$, respectively $(n=4)$.

The initial concentration of dopamine was $100 \mu \mathrm{M}$ in most experiments (with $20 \mu \mathrm{M}$ ascorbic acid), but this was subject to degradation. We assessed actual concentration of dopamine in our recording chamber at the time of conditioning (i.e., the end of the $12.5 \mathrm{~min}$ application), by the use of high-performance liquid chromatography (in collaboration with Dr. J.-P. Tassin, College de France, Paris, France). Our measurement showed that dopamine concentration in the bath was $79 \mu \mathrm{M}$. We verified also that the $20 \mu \mathrm{M}$ level of ascorbic acid does not affect the synaptic responses. Thus, ascorbic acid alone was applied twice for a $12.5 \mathrm{~min}$ duration, separated by a $40 \mathrm{~min}$ interval, as for our principal dopamine double-application protocol (see Fig. 1d). There were no significant changes in the EPSP slope during and after the ascorbic acid application. Percentage changes of the EPSP slope $40 \mathrm{~min}$ after the first and second applications of ascorbic acid were $-2.9 \pm 4.7 \%(n=6)$ and $-1.4 \pm$ $5.2 \%$, respectively ( $n=5$; recording of one cell was lost just after the second application).

For statistical analysis, a $p<0.05$ confidence level was considered significant. Unless otherwise specified, the two-tailed Student's $t$ test was used. All values are expressed as mean \pm SEM. As described previously, morphological identification of pyramidal neurons was routinely performed using biocytin [1.5\% loaded in recording electrodes (Otani et al., 1999)]. All identified neurons were classified as layer V pyramidal neurons, based on the shape and location of their cell body and on the long apical dendrite bearing a tuft, which occurs in the superficial layer.

The following drugs were used: bicuculline methiodide (Sigma, St. Quentin Fallavier, France), biocytine (Sigma), dopamine (Sigma), BAPTA (Sigma), $\quad R(+)$-7-chloro-8-hydroxy-3-methyl-1-phenyl2,3,4,5-tetrahydro-1 H-3-benzazepine hydrochloride (SCH23390) (Tocris Cookson, Bristol, UK), sulpiride (Tocris Cookson), (+)-1Phenyl-2,3,4,5-tetrahydro-( $1 H$ )-3-benzazepine-7,8-diol hydrobromide (SKF38393) (Tocris Cookson), quinpirole (Tocris Cookson), DL-2-amino-5-phosphonopentanoic acid (AP-5) (Tocris Cookson), 6-cyano-7-nitroquinoxaline-2,3-dion (CNQX) (Tocris Cookson), and $(R S)$ - $\alpha$-methyl-4-carboxyphenylglycine (MCPG) (Tocris Cookson).

\section{Results}

\section{LTP induction is facilitated by dopamine priming}

The glutamatergic monosynaptic EPSP was evoked by layer I-II afferent stimulation and recorded from the soma of layer $\mathrm{V}$ pyramidal neurons in PFC slices prepared from juvenile rats (23-30 $\mathrm{d}$ of age) (Fig. 1a). Perfusion of the PFC slices with a relatively high concentration of dopamine $(100 \mu \mathrm{M})$ for an extended period of time $(12.5 \mathrm{~min})$ resulted in a transient decrease of synaptic efficacy that lasted no $>30 \mathrm{~min}$ (Fig. 1c) (first dopamine application, $n=6$ ) (Otani et al., 1998, 1999). The dopamine application alone did not induce lasting synaptic changes unlike in the hippocampus (Huang and Kandel, 1995; Sajikumar and Frey, 2004). When dopamine was applied for the second time, however, the depression of the EPSP was significantly smaller (Fig. 1c) $(-36 \pm$ $7.6 \%$ change by the first application vs $-16 \pm 4.3 \%$ by the second application; $p<0.05$, paired $t$ test). Although the molecular mechanism underlying this dopamine-induced acute reduction of the EPSP is unknown, the clear habituation indicates that the low dopamine condition in slices had induced a homeostatic compensation in the dopamine system (Grace, 1991). Indeed, in PFC slices, a significant amount of endogenous release of dopa- 

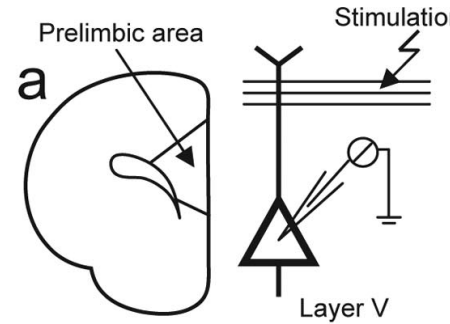

(Bregma $2.2-3.7 \mathrm{~mm}$ ) pyramidal cell
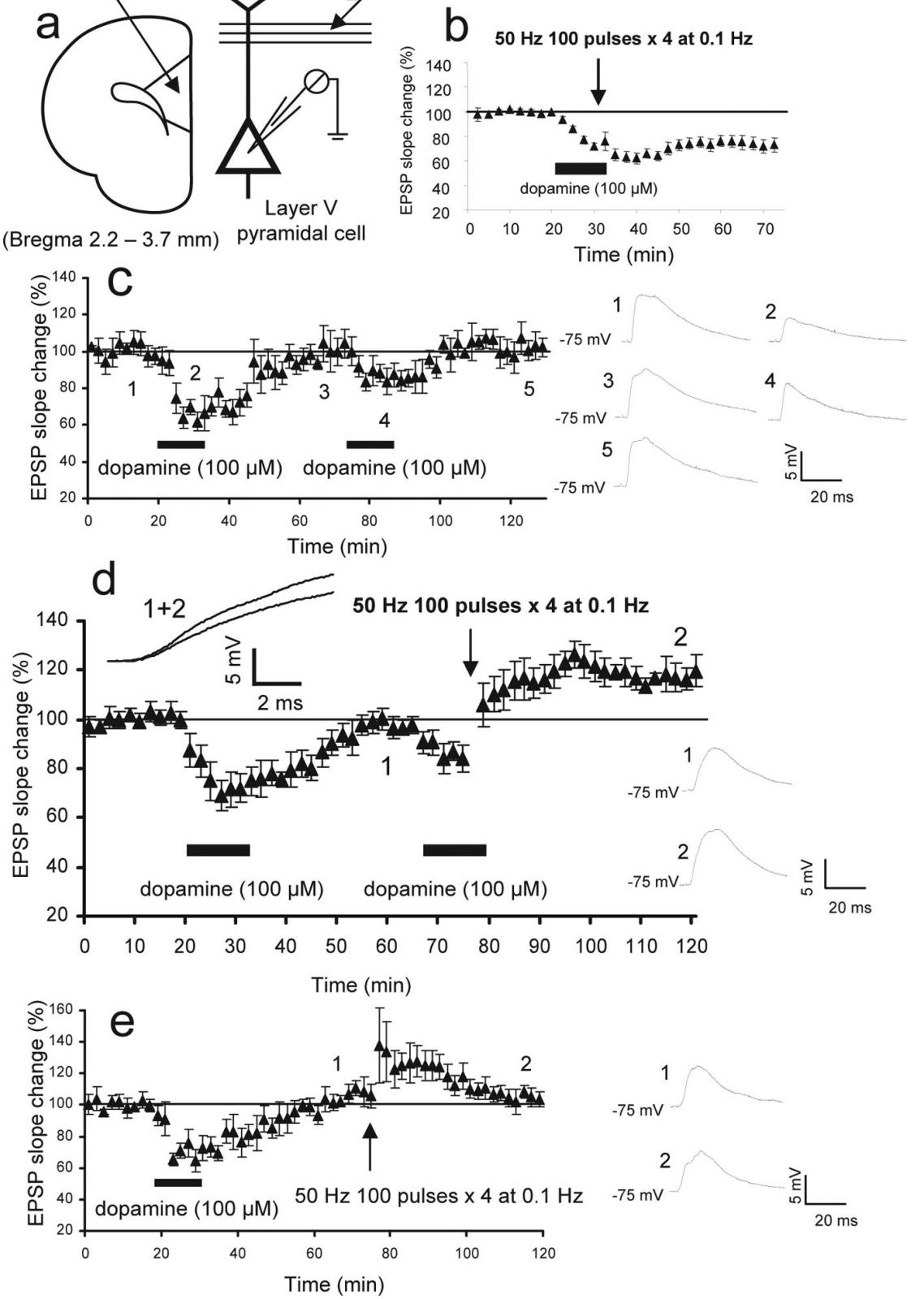

Figure 1. Priming of dopamine receptors facilitates LTP induction in rat PFC neurons. $\boldsymbol{a}$, The monosynaptic glutamatergic EPSP was evoked by $0.033 \mathrm{~Hz}$ test stimuli applied to layer I-II fibers of the PFC slices and recorded at somatic level from layer V pyramidal neurons by the use of sharp micro pipettes. Bicuculline $(1 \mu \mathrm{m})$ was routinely added in the bathing medium to reduce GABA inhibition. $\boldsymbol{b}$, Data taken from our previous experiments (Otani et al., 1999) showing that the delivery of $50 \mathrm{~Hz}$ tetanic stimuli (100 pulses, 4 times at $0.1 \mathrm{~Hz}$ ) in the presence of dopamine ( $100 \mu \mathrm{m} ; 12.5 \mathrm{~min}$ ) induces LTD of the EPSP $(n=14)$. This LTD induction is NMDA receptor independent (0tani et al., 1998). Tetanic stimulation alone or dopamine application alone does not induce lasting plasticity (Otani et al., 1998, 1999). c, When dopamine application (100 $\mu \mathrm{m} ; 12.5 \mathrm{~min}$ ) is repeated, the transient reduction of the EPSP shows marked habituation ( $-36 \pm 7.6 \%$ by the first application vs $-16 \pm 4.3 \%$ by the second application; $n=6$; $p<0.05$, paired $t$ test). This fact indicates that in slices, hypodopaminergic condition induced homeostatic compensations of the dopamine system. $\boldsymbol{d}$, Delivery of $50 \mathrm{~Hz}$ tetani in association with the second application of dopamine induces LTP $(20 \pm 3.0 \%$ increase 40 min after dopamine/tetani; $n=10 ; p<0.00001$ compared with the tetani-alone group). Averaged responses taken from the indicated time points ( 1 and 2 ) are shown in the insets. The same responses are superimposed with a longer time scale to show the clear difference in the rising slope of the EPSP. $\boldsymbol{e}$, The second application of dopamine is necessary for LTP. Delivery of $50 \mathrm{~Hz}$ stimuli alone, $40 \mathrm{~min}$ after the first application of dopamine, induced only decaying potentiation ( $2.4 \pm 4.2 \% 40 \mathrm{~min}$ after tetani; $n=8 ; p<0.005)$. Averaged EPSPs taken from the indicated time points are shown in the insets.

As shown in Figure $1 b$, when the first application of dopamine was paired with a weak tetanic stimulation $(50 \mathrm{~Hz} ; 100$ pulses; four times at $0.1 \mathrm{~Hz}$ ), an NMDA receptor-independent LTD was induced $(-25 \pm 6.0 \%$ at $40 \mathrm{~min} ; n=14)$ (Otani et al., 1998, 1999). This weak tetanus itself induced no lasting plasticity $(0.1 \pm 1.2 \%$ at $40 \mathrm{~min} ; n=12$; data not shown) (Otani et al., 1998, 1999). In the next series of experiments, we applied dopamine first without concurrent application of the 50 $\mathrm{Hz}$ stimuli (Fig. 1d). When the dopamineinduced acute depression had fully reversed (40 min later), dopamine was reapplied in an identical manner. This second application of dopamine was paired with the same weak tetanic stimulation described above. Remarkably, this procedure induced LTP (Fig. 1d). The EPSP slope was $20 \pm 3.0 \%$ above baseline $40 \mathrm{~min}$ after dopamine and tetani $(n=10 ; p<0.00001$ compared with the tetanus-alone control group, which showed $0.1 \pm 1.2 \%$ change at $40 \mathrm{~min}$; two-tailed $t$ test). The second application of dopamine was necessary for the induction of LTP. When omitted, the $50 \mathrm{~Hz}$ tetani induced only decaying potentiation (Fig. $1 e)(2.4 \pm 4.2 \%$ at $40 \mathrm{~min} ; n=$ $8 ; p<0.005$; compared with the group depicted in Fig. 1d).

Two sets of control experiments were performed. First, to exclude the possibility that prolonged dialysis of the postsynaptic cells facilitated the induction of LTP, we performed the dialysis of postsynaptic neurons for an extended period of time ( $>1 \mathrm{~h}$ recording) before the application of dopamine (Fig. $2 a$; see legend for more details of the method). Under this condition, the $50 \mathrm{~Hz}$ tetani still induced a small but significant LTD $(-8.2 \pm 4.9 \% ; n=6 ; p<$ 0.0002 compared with the group depicted in Fig. $1 d$, and $p<0.05$ compared with the tetanus-alone control group). Second, one may argue that a smaller synaptic depression (habituation) induced by the second application of dopamine may lead to the induction of LTP. To exclude this possibility, we applied 10-30 $\mu \mathrm{M}$ (rather than 100 $\mu \mathrm{M})$ of dopamine, again after a prolonged postsynaptic dialysis (Fig. 2b). These concentrations of dopamine induced acute depression $(-16 \pm 5.2 \%)$ similar in degree to that induced by the second application of $100 \mu \mathrm{M}$ dopamine $(-16 \pm$ $4.3 \%$ ). However, delivery of $50 \mathrm{~Hz}$ tetani in the presence of the $10-30 \mu \mathrm{M}$ dopamine induced LTD, but not LTP $(-15 \pm 6.8 \%$;

mine may not be present unless residual axons receive highfrequency input (Young and Yang, 2005). It is then thought that the second application of dopamine better models physiological dopamine effects than the first application. $n=5 ; p<0.0005$ compared with the group depicted in Fig. $1 d$, and $p<0.01$ compared with the tetanus-alone control group). From these experiments, we conclude that for the induction of LTP, both preapplication of dopamine and the pairing of a sec- 
a

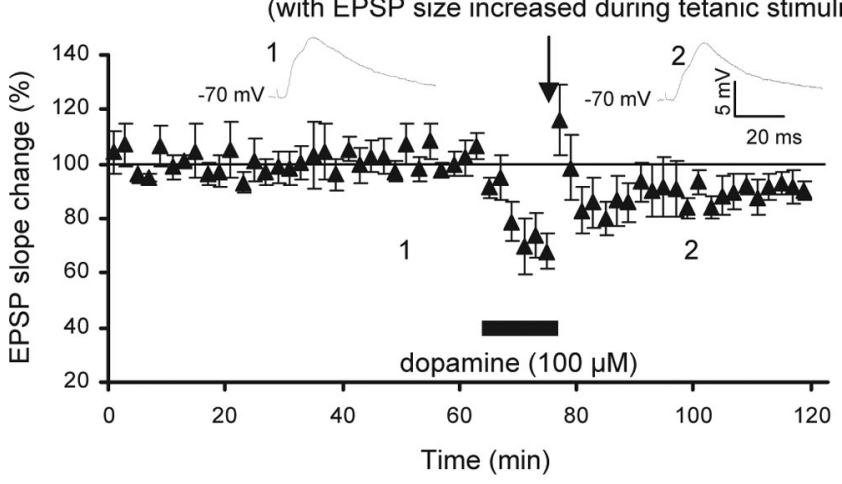

b

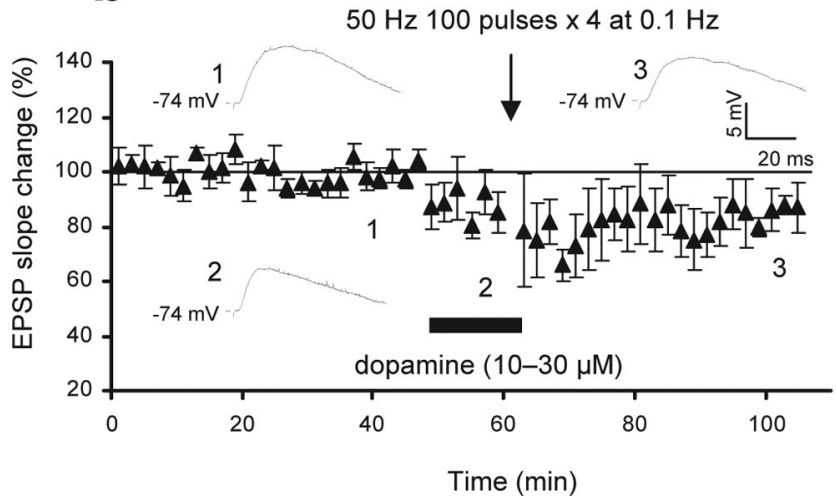

Figure 2. Experiments to establish the dopamine-facilitated LTP. $\boldsymbol{a}$, In this set of experiments $(n=6)$, the dialysis of postsynaptic cells during the long preconditioning response recording ( $>1 \mathrm{~h}$ ) (Fig. 1d) was controlled. In addition, we equally controlled the smaller acute synaptic depression (habituation) seen with the second application of dopamine (Fig. 1, compare $b$ and $d$ ). Thus, after long-term recording of baseline responses at $0.033 \mathrm{~Hz}$, dopamine (100 $\mu \mathrm{m} ; 12.5 \mathrm{~min}$ ) was identically applied. Just before the delivery of tetani, the EPSP slope was increased to baseline level by increasing the stimulus intensity. Under this condition, $50 \mathrm{~Hz}$ stimuli did not induce LTP $(-8.2 \pm 4.9 \% ; p<0.0002)$. Averaged EPSPs taken from indicated time points are shown in the insets. $\boldsymbol{b}$, In this set of experiments, we controlled the smaller acute synaptic depression (habituation) seen with the second dopamine (Fig. 1d) by the use of lower concentrations of dopamine (10-30 $\mu \mathrm{m} ; 12.5 \mathrm{~min} ; n=5)$. Therefore, again after a long baseline recording (to control postsynaptic dialysis), the application of these concentrations of dopamine induced a reduction in the EPSP slope $(-16 \pm 5.2 \%)$ similar to that induced by the second application of $100 \mu \mathrm{m}$ dopamine $(-16 \pm 5.7 \%$ ) (Fig. 1d). Delivery of $50 \mathrm{~Hz}$ stimuli in the presence of 10-30 $\mu$ m dopamine, however, induced LTD $(-15 \pm 6.8 \% ; n=5 ; p<$ 0.0001). Averaged EPSPs taken from indicated time points are shown in the insets.

ond application of dopamine with weak tetanic stimulation are necessary. We will refer to the prestimulation of dopamine receptors as priming and the pairing of dopamine application with the $50 \mathrm{~Hz}$ tetani as "induction."

\section{Involvement of dopamine $D_{1}$ and $D_{2}$ receptors in LTP}

With a novel LTP protocol established, we then determined the subtype of dopamine receptors involved in this LTP. All pharmacological experiments hereafter were performed in interleaved manner. First, the $\mathrm{D}_{1}$ antagonist SCH23390 ( $\left.1 \mu \mathrm{M} ; n=6\right)$ (Fig. $3 a$ ) or the $\mathrm{D}_{2}$ antagonist sulpiride $(10 \mu \mathrm{M} ; n=6)$ (Fig. $3 b$ ) was bath-applied during the priming phase. Neither antagonist changed baseline EPSP nor the degree of acute depression induced by dopamine $(-32 \pm 9.7 \%$ with SCH23390; $-27 \pm 11 \%$ with sulpiride; $p>0.3$ compared with the acute depression induced by the first dopamine in Fig. 1d). Forty minutes after drug application, dopamine was applied for the second time and paired to $50 \mathrm{~Hz}$ tetani. In both antagonist groups, LTP was blocked $(0.5 \pm 5.8 \%, p<0.01$ and $-8.3 \pm 5.2 \%, p<0.0002$, respectively, compared with Fig. $1 d$ ) (see Fig. $3 e$ for summary graph), suggesting that both $\mathrm{D}_{1}$ and $\mathrm{D}_{2}$ receptors must be prestimulated (primed) to facilitate a later induction of LTP. Second, SCH23390 (1 $\mu \mathrm{M} ; n=7)$ (Fig. $3 c$ ) or sulpiride $(10 \mu \mathrm{M} ; n=7)$ (Fig. $3 d$ ) was applied during the induction phase. In both groups, LTP was blocked $(-8.6 \pm 4.8 \%, p<0.0001$ and $-13 \pm 7.1 \%$, $p<0.002$, compared with Fig. $1 d$ ) (see Fig. $3 f$ for summary graph). Thus, induction also requires the concurrent activation of $\mathrm{D}_{1}$ and $\mathrm{D}_{2}$ receptors.

Based on the above experiments, one may argue that LTP was blocked by the SCH23390 or sulpiride applied during the priming phase because of insufficient washout of these antagonists at the time of induction. To eliminate this possibility, we used dopamine agonists. If both $\mathrm{D}_{1}$ and $\mathrm{D}_{2}$ receptors are necessary for priming, a combined application of $\mathrm{D}_{1}$ and $\mathrm{D}_{2}$ agonists as priming stimulus should facilitate LTP, whereas a lone application of either agonist should fail to facilitate LTP. This LTP after the combined application could not be explained by the presence of residual agonists at the time of induction, because the additional receptor stimulation by residual agonists in the presence of 100 $\mu \mathrm{M}$ dopamine is unlikely to convert LTD to LTP. Thus, as the priming stimulus, $\mathrm{D}_{1}$ agonist SKF38393 (25-50 $\left.\mu \mathrm{M} ; n=8\right), \mathrm{D}_{2}$ agonist quinpirole ( $25 \mu \mathrm{M} ; n=7$ ), or SKF38393 plus quinpirole (25 and $25 \mu \mathrm{M} ; n=6$ ) were bath-applied for $12.5 \mathrm{~min}$. Forty minutes after this application, a dopamine application was paired with $50 \mathrm{~Hz}$ stimuli. LTP could only be induced after the combined SKF38393 plus quinpirole application (Fig. $3 g)(24 \pm 5.0 \%$ at $40 \mathrm{~min} ; p<0.001$ compared with tetanus-alone control group). We conclude that priming involves the activation of both $\mathrm{D}_{1}$ and $\mathrm{D}_{2}$ receptors.

\section{Involvement of NMDA receptors in priming and induction}

Blockade of NMDA receptors within the PFC retards operant learning (Baldwin et al., 2002). Moreover, abuse with NMDA receptor antagonist phencyclidine disrupts $\mathrm{PFC}$-dependent cognitive function (Egerton et al., 2005). Assuming that NMDA receptor-dependent synaptic plasticity is important for PFCdependent cognitive processes, we tested the role of the NMDA receptors in specific phases (i.e., priming or induction) of the PFC LTP. First, we applied the NMDA receptor antagonist DLAP-5 $(100 \mu \mathrm{M})$ during priming (Fig. $4 a)(n=7)$. AP-5 caused a slight reduction in baseline EPSP, but this effect was transient, as verified in separate neurons $(-1.0 \pm 6.4 \%, 40 \mathrm{~min}$ after washout; $n=7)$. The presence of AP- 5 during priming nullified the priming effect. Therefore, pairing of the second dopamine perfusion with $50 \mathrm{~Hz}$ tetani resulted in LTD instead of LTP $(-18 \pm 6.3 \%$; $p<0.0001$ compared with the group depicted in Fig. $1 d)$. Next, we applied AP-5 during the induction phase (Fig. $4 c, d)(n=9)$. In this case, interestingly, five cells showed clear LTP $(31 \pm 4.1 \%)$ (Fig. 4c), and the other four showed degrees of LTD $(-31 \pm$ 17\%) (Fig. $4 d$ ). There was no difference in morphological characteristics and membrane properties between these two groups of neurons. Importantly, this AP-5 effect could generate a net "noLTP" result in field recording. This may have occurred in two previous studies in which AP-5 blocked induction of PFC LTP (Gurden et al., 1999; Huang et al., 2004). Together, these data suggest that NMDA receptor-mediated synaptic transmission is necessary for priming and contributes to induction in a subpopulation of PFC neurons.

Many forms of synaptic plasticity in various brain regions depend on metabotropic glutamate receptors (mGluRs). We therefore tested whether the present form of LTP also requires the 

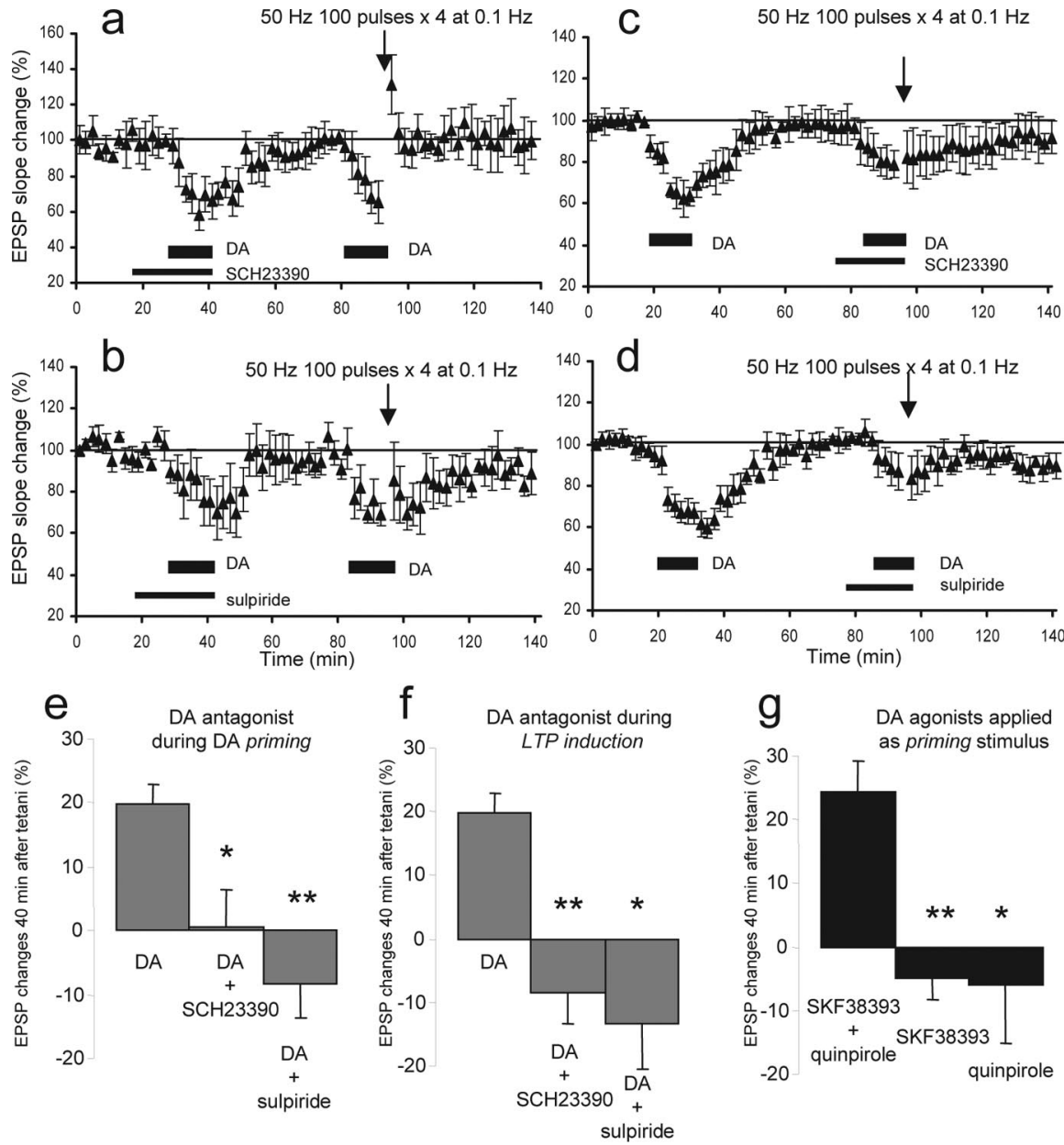

Figure 3. Concurrent activation of dopamine $D_{1}$ and $D_{2}$ receptors is necessary for both priming and induction of the LTP. $\boldsymbol{a}$, The presence of $\mathrm{D}_{1}$ receptor antagonist $\mathrm{SCH} 23390(1 \mu \mathrm{M})$ from $10 \mathrm{~min}$ before the first application of dopamine (100 $\left.\mu \mathrm{m} ; 12.5 \mathrm{~min}\right)$ until the end of the application blocked LTP by the second dopamine- $50 \mathrm{~Hz}$ tetani paring $(0.5 \pm 5.8 \%$ change 40 min after the second dopamine/tetani; $n=6 ; p<0.01)$. $\boldsymbol{b}$, The presence of $D_{2}$ antagonist sulpiride (10 $\left.\mu \mathrm{m}\right)$ during the first application of dopamine also blocked the LTP by the second dopamine-tetani pairing $(-8.3 \pm 5.2 \% ; n=6 ; p<0.0002)$. $c$, The presence of $\mathrm{SCH} 23390(1 \mu \mathrm{M})$ from $10 \mathrm{~min}$ before the second application of dopamine until the end of the application and tetani blocked the induction of $\operatorname{LTP}(-8.6 \pm 4.8 \% ; n=7 ; p<0.0001)$. $\boldsymbol{d}$, The presence of sulpiride (10 $\mu \mathrm{m})$ during the second application of dopamine and tetani also blocked the LTP $(-13 \pm 7.1 \% ; n=7 ; p<0.002) . e$, Summary graph showing the EPSP slope changes $40 \mathrm{~min}$ after the second dopamine (DA)-tetani paring in three different priming conditions. Left (DA), The condition in which dopamine alone was applied as priming stimulus and $20 \%$ LTP was induced $(n=10)$ (see Fig. $1 d$ ). Middle (DA + SCH23390), The group depicted in Figure $3 a(n=6)$ in which $D_{1}$ receptors were blocked by $S \mathrm{CH} 23390$ during the first application of dopamine and LTP was absent $(p<0.01)$. Right (DA+sulpiride), The group depicted in $\boldsymbol{b}(n=6)$ in which $\mathrm{D}_{2}$ receptors were blocked by sulpiride during the first application of dopamine and LTP was absent $(p<0.0002)$. $f$, Summary graph showing the EPSP slope changes 40 min after the second dopamine-tetani paring in three different induction conditions. Left (DA), The condition in which dopamine alone was applied as priming stimulus and 20\% LTP was induced $(n=10)$ (Fig. $1 d$ ). Middle (DA+SCH23390), The group depicted in $\mathrm{C}(n=7)$ in which $\mathrm{SCH} 23390(1 \mu \mathrm{m})$ was present during the second application of dopamine and tetani. LTP was absent. Right (DA+sulpiride), The group depicted in $\boldsymbol{d}(n=7)$ in which sulpiride (10 $\mu \mathrm{m})$ was present during the second application of dopamine and tetani. LTP was also absent. $\boldsymbol{g}$, Summary graph showing the EPSP slope changes 40 min after the second dopamine-tetani paring in three different agonist conditions. Left (SKF38393 + quinpirole), $\mathrm{D}_{1}$ agonist SKF38393 (25 $\left.\mu \mathrm{m}\right)$ and $\mathrm{D}_{2}$ agonist quinpirole $(25 \mu \mathrm{m})$ were applied together for 12.5 min as priming stimulus $(n=6)$. Forty minutes after the agonist application, $50 \mathrm{~Hz}$ tetani were delivered in the presence of dopamine $(100 \mu \mathrm{m})$. There was LTP (24 $\pm 5.0 \% 40 \mathrm{~min}$ after the dopamine-tetani paring). Middle (SKF38393), D agonist SKF38393 (25-50 $\mu \mathrm{m}$ ) was applied for $12.5 \mathrm{~min}$ as priming stimulus $(n=8)$. Forty minutes after the SKF38393 application, $50 \mathrm{~Hz}$ tetani were delivered in the presence of dopamine $(100 \mu \mathrm{M})$. There was no LTP ( $-4.8 \pm 3.4 \%$ at $40 \mathrm{~min} ; n=8 ; p<0.001$ compared with the SKF+quinpirole group). Right (quinpirole), $\mathrm{D}_{2}$ agonist quinpirole $(25 \mu \mathrm{m})$ was applied as priming stimulus $(n=7)$, and $40 \mathrm{~min}$ after quinpirole, $50 \mathrm{~Hz}$ tetani were delivered in the presence of dopamine (100 $\mu \mathrm{m})$. There was no LTP $(-5.9 \pm 9.3 \%$ at $40 \mathrm{~min} ; n=7 ; p<0.02)$. Error bars represent SEM. tion is mGluR dependent. The presence of MCPG during the priming phase also blocked LTP $(2.3 \pm 7.0 \% ; n=7 ; p<0.05$ compared with Fig. 1d; data not shown). However, the mGluR involvement in priming remains inconclusive at this stage, because it is possible that MCPG is not fully washed out by the time of induction. When $50 \mathrm{~Hz}$ stimulation was paired with dopamine perfusion 40 min after sole application of MCPG (300 $\mu \mathrm{M} ; 22.5 \mathrm{~min})$, the LTD induction that normally occurs after pairing (Otani et al., 1998) was found to be blocked $(3.3 \pm 11 \% ; n=5$; data not shown). This suggests that there may be residual MCPG at the time of induction, which may block induction of plasticity (Otani et al., 1999).

\section{Postsynaptic mechanisms of the dopamine-facilitated LTP}

A number of experiments were performed to address the cellular mechanisms underlying the dopamine-primed, NMDA receptor-dependent LTP. First, to determine the induction locus, hyperpolarizing currents (to $-110 \mathrm{mV}$ ) were applied through recording electrodes during the application of $50 \mathrm{~Hz}$ tetani to counteract tetanus-induced postsynaptic depolarization $(n=6)$ (Fig. 6a). Under this condition, the LTP was blocked $(-5.5 \pm 7.1 \%$; $p<0.002$ compared with the group depicted in Fig. 1d). Second, the $\mathrm{Ca}^{2+}$ chelator BAPTA (50-100 mM in recording electrodes) was injected into postsynaptic sites before the experiments $(n=6)$ (Fig. $6 b)$. The application of BAPTA also blocked LTP $(-4.0 \pm 8.5 \% ; p<0.01$ compared with Fig. $1 d$ ). Together, these results suggest that the induction of this novel form of LTP requires both postsynaptic depolarization during tetanus and postsynaptic increases in $\mathrm{Ca}^{2+}$ level. Next, we tested whether dopamine primes the PFC LTP by potentiating the NMDA receptormediated EPSP (Zheng et al., 1999; Seamans et al., 2001). To test this, NMDA receptor-mediated EPSP was pharmacologically isolated (Fig. 4b, left traces), and dopamine was identically applied (100 $\mu \mathrm{M} ; 12.5 \mathrm{~min})$. The dopamine caused a rapid and transient reduction, but not potentiation, of the NMDA receptormediated EPSP $(n=6)$ (Fig. $4 b)$. We conclude that the priming effect of dopamine is not caused by a potentiation of NMDA receptors. activation of mGluRs. When the common mGluR antagonist $(R S)-\mathrm{MCPG}(300 \mu \mathrm{M})$ was present during the induction phase, LTP was blocked $(-26 \pm 7.7, p<0.0001$ compared with the group depicted in Fig. $1 d ; n=6$ ) (Fig. 5). Thus, the LTP induc-
Time-dependent facilitation of LTP by continuous application of low concentration of dopamine

Thus far, we used the spaced (40 min interval) doubleapplication of a relatively high concentration of dopamine to 
provide background dopamine signal and induce LTP. Using brain microdialysis, a method that detects only dopamine increases resulting from tonic release (Floresco et al., 2003), Bassareo and Di Chiara (1997) have indeed shown large and repeated augmentations of dopamine concentration in rat PFC during goal-directed behavior $(\sim 100 \%$ increases with $120 \mathrm{~min}$ interval). Furthermore, the doubleapplication method was ideal to isolate dopamine signal specifically involved in LTD-LTP conversion (priming). However, an alternative and perhaps more physiologically relevant way of providing background dopamine signal is through a continuous perfusion of a low concentration of dopamine. Therefore, in the final set of experiments, we continuously applied dopamine at $3 \mu \mathrm{M}$ in the bath. This concentration was chosen because this was approximately the lowest concentration of exogenously applied dopamine to induce visible changes in the slope of the evoked EPSP (i.e., a small decrease or increase; the average change was $5.2 \pm 5.0 \%$ at $12.5 \mathrm{~min}$ after the beginning of perfusion, $n=8$, and $-3.7 \pm 8.6 \%$ at the end of the experiments, $n=7$ ) (Fig. $7 a$, open circles). Interestingly, the continuous perfusion of 3 $\mu \mathrm{M}$ dopamine before $50 \mathrm{~Hz}$ tetani (for 40 min) was sufficient to promote LTP $(32 \pm$ $14 \%, 40$ min after tetani; $n=7 ; p<0.025$ compared with the above no-tetanus group) (Fig. $7 a$, black triangles). In contrast, a $12.5 \mathrm{~min}$ perfusion before the tetani was insufficient for LTP $(2.1 \pm 7.4 \% ; n=10 ; p>0.4$ compared with the above no-tetanus group, and $p<0.05$ compared with the 40 min perfusion group) (Fig. $7 a$, gray triangles). These results suggest that the priming effect requires $12.5-40 \mathrm{~min}$ to develop. Our preliminary experiments (in preparation) show that this LTP also requires the activation of both $\mathrm{D}_{1}$ and $\mathrm{D}_{2}$ receptors and NMDA receptors. Interestingly (Fig. $7 b$ ), when $50 \mathrm{~Hz}$ stimulation was paired with 100 $\mu \mathrm{M}$ dopamine superimposed on the background concentration of $3 \mu \mathrm{M}$ dopamine, the tetanus equally induced LTP but not LTD $(24 \pm 14 \% ; n=7 ; p<0.005$ compared with the LTD group depicted in Fig. 1b). Thus, LTD (Fig. 1b) was converted to LTP (Fig. $7 b$ ) also by the continuous application of a low concentration of dopamine.

\section{Discussion}

Using PFC slices prepared from juvenile rats, we discovered that prestimulation of $\mathrm{D}_{1}$ and $\mathrm{D}_{2}$ dopamine receptors (priming) converts NMDA receptor-independent LTD (Otani et al., 1998) to LTP. This conversion depends on the activation of NMDA receptors during the priming process. NMDA receptor involvement in the induction phase of this LTP was not as clear; however, it was clearly shown that induction requires $\mathrm{mGluR}$ activation. The dopamine priming was achieved by two different protocols: (1) phased exposure $(12.5 \mathrm{~min})$ to a relatively high concentration of dopamine $(100 \mu \mathrm{M})$; and (2) the continuous application of a low concentration of dopamine $(3 \mu \mathrm{M})$. With the latter method, we showed that priming requires $12.5-40 \mathrm{~min}$ to develop.

It is widely believed that levels of tonic background dopamine

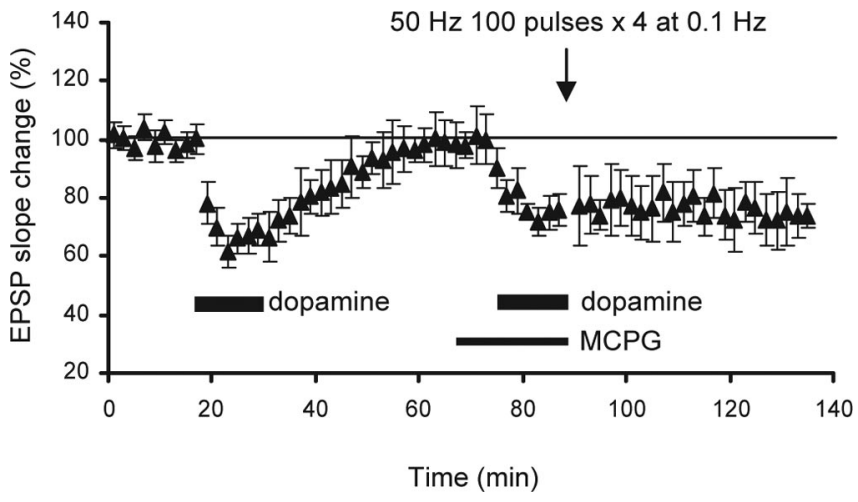

Figure 5. Induction of LTP requires the activation of mGluRs. The presence of MCPG (300 $\mu \mathrm{m})$ from $10 \mathrm{~min}$ before the second application of dopamine until the end of the application and tetani blocked the induction of LTP and rather resulted in LTD ( $-27 \pm 7.7 \%, 40$ min after second dopamine and tetani; $p<0.0001 ; n=6$ ). The presence of MCPG during priming also blocked LTP $(2.3 \pm 7.0 \% ; n=7 ; p<0.05$; data not shown). However, the involvement of mGluRs during priming cannot be firmly concluded, because MCPG applied during priming may not be completely washed out by the time of induction (see Results, Involvement of NMDA receptors in priming and induction).

concentration regulate cognitive functions (Grace, 1991; Schultz, 1998, 2002; Akil et al., 1999; Goto and Grace, 2005). A recent theoretical study suggested that novelty-related increases in tonic dopamine inputs in the hippocampus facilitate LTP and memory encoding (Lisman and Grace, 2005). However, previous experimental studies in the PFC (Gurden et al., 1999; Huang et al., 2004), striatum (Reynolds et al., 2001), and hippocampus (Frey et al., 1991) limited their focus to possible effects of fast phasic release of dopamine on LTP. Although rapid release of dopamine 


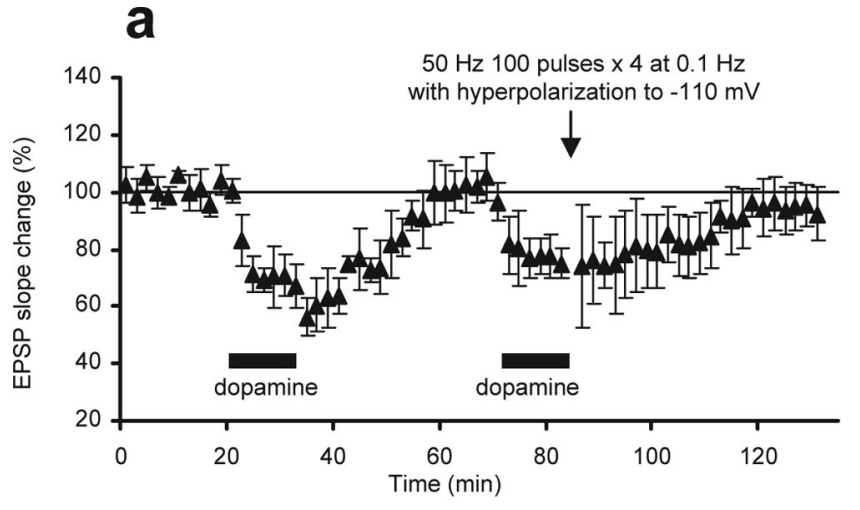

b BAPTA injected cells

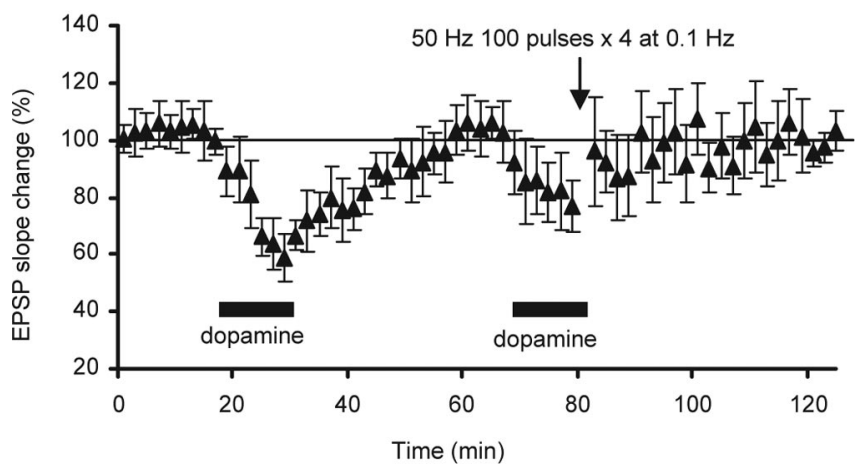

Figure 6. Postsynaptic locus of dopamine-facilitated LTP. $\boldsymbol{a}$, LTP induction requires postsynaptic depolarization. During the delivery of $50 \mathrm{~Hz}$ tetani in the presence of the second dopamine, postsynaptic membrane was hyperpolarized to $-110 \mathrm{mV}$ to counteract tetanus-induced depolarization. Under this condition, LTP induction was blocked $(-5.5 \pm 7.1 \%, 40$ min after the second dopamine-tetani paring; $n=6 ; p<0.002$ ). $\boldsymbol{b}$, LTP induction requires postsynaptic increases of $\left[\mathrm{Ca}^{2+}\right]$. The $\mathrm{Ca}^{2+}$ chelator BAPTA (50-100 mm included in recording pipettes) was injected into postsynaptic sites before the experiments. Diffusion of BAPTA, which was verified by a block of $\mathrm{Ca}^{2+}$-dependent spike-train adaptation, did not change baseline EPSP. Under this condition, dopamine-facilitated LTP was blocked ( $-4.0 \pm 8.5 \%$ at $40 \mathrm{~min} ; n=6$; $p<0.01)$.

during brief high-frequency input does facilitate synaptic plasticity in the PFC (Young and Yang, 2005; our observation), no studies have as yet explored the role of the background presence of dopamine in synaptic plasticity. Using PFC slices, which are mostly deprived of tonic dopamine inputs, we thus revealed that the background dopamine signal permits the induction of LTP in the PFC. This may explain why LTP can be easily induced by tetanus alone in the intact PFC (Gurden et al., 1999), where basal levels of dopamine are tonically maintained (Takahata and Moghaddam, 2000). We discovered furthermore that the priming by dopamine requires concurrent low-frequency stimulation of NMDA receptors (Fig. 4a). Previously, NMDA receptors in the PFC were implicated in the generation of delay period activity (Brunel and Wang, 2001) as well as induction of LTP (Gurden et al., 1999; Huang et al., 2004). Our result thus adds an important and novel role for the NMDA receptors in PFC plasticity; that is, a preparatory regulation for dopamine-dependent induction of LTP.

In our in vitro procedure, at least $4 \mathrm{~h}$ elapsed between slice preparation and the first bath-application of dopamine. Because dopamine receptors are tonically stimulated in the intact brain, this time course suggests that the priming triggered in vivo fades during the $4 \mathrm{~h}$ of the in vitro incubation (Fig. 1, compare $b$ and $d$ ). Such an extremely low dopamine condition may not occur in the

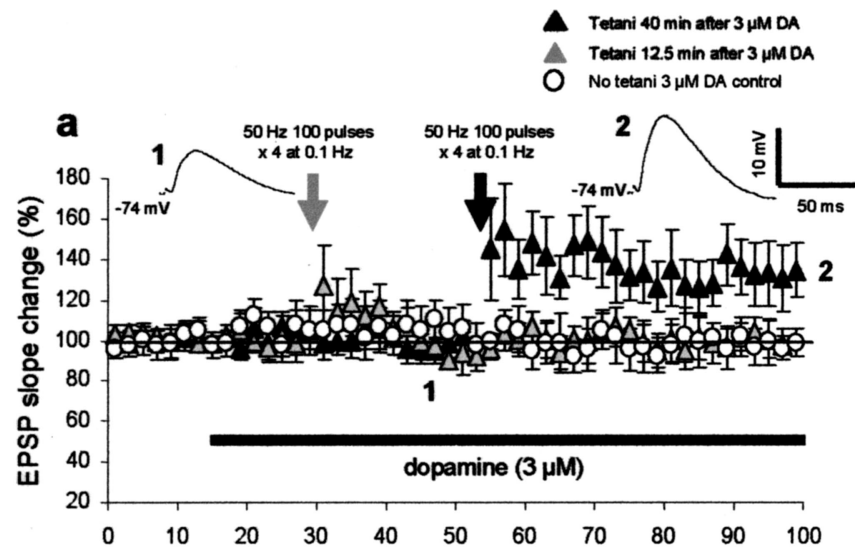

b

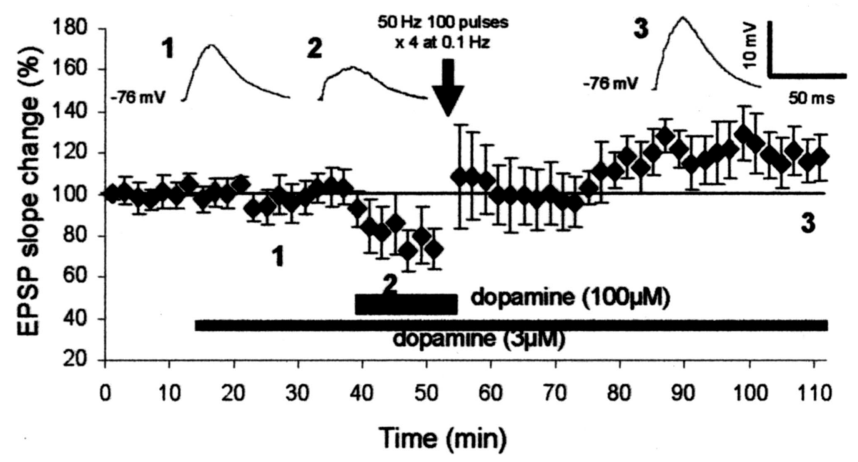

Figure 7. Continuous presence of low concentration of dopamine $(3 \mu \mathrm{m})$ for $40 \mathrm{~min}$ before tetani facilitates the induction of LTP and prevents the induction of LTD. $\boldsymbol{a}$, In the first group (gray triangles), $3 \mu$ m dopamine was perfused in the bath for $12.5 \mathrm{~min}$ before the delivery of 50 Hz tetani. No LTP was induced ( $2.1 \pm 7.4 \%, 40$ min after tetani; $n=10$ ). In the second group (black triangles), $3 \mu \mathrm{m}$ dopamine was perfused for $40 \mathrm{~min}$ before the tetani delivery. In this case, the $50 \mathrm{~Hz}$ tetani induced LTP $(32 \pm 14 \% ; p<0.05 ; n=7)$. Averaged EPSPs taken from the indicated time points are shown in the insets for this LTP group. In the third group (open circles), $3 \mu \mathrm{m}$ dopamine was perfused without delivery of tetani for the entire duration of the experiments $(n=8)$. $\boldsymbol{b}$, The $3 \mu \mathrm{m}$ dopamine was identically applied as above, and $12.5 \mathrm{~min}$ before the delivery of $50 \mathrm{~Hz}$ tetani, dopamine concentration was increased to $100 \mu \mathrm{m}$ until the end of the tetani. Under this condition, the tetani-100 $\mu$ m dopamine paring induced LTP ( $24 \pm$ $14 \%, 40$ min after tetani; $n=7 ; p<0.005$ ) but not LTD. Averaged EPSPs taken from the indicated time points are shown in the insets.

intact PFC, but reduced levels of tonic dopamine inputs may indeed be present in the PFC of schizophrenics (Akil et al., 1999). We showed equally that the lack of baseline activation of NMDA receptors converts LTP to LTD (Fig. 4a). Again, in schizophrenic PFC, NMDA receptor dysfunction may exist (Sokolov, 1998). In this regard, we add that chronic administration of NMDA receptor antagonists disrupts PFC-dependent cognitive function (Egerton et al., 2005).

Together, we suggest that a pathological conversion of LTP to LTD may occur in the PFC when the level of basal stimulation of dopamine and NMDA receptors is low. Such an abnormal conversion would disrupt long-term neuronal representations within the PFC and impair the context-dependent selection of action repertories, a cognitive component necessary for the realization of goal-directed behavior (Fuster et al., 2000; Miller and Cohen, 2001; Otani, 2002). The slow and durable increases of extracellular dopamine concentration (Bassareo and Di Chiara, 1997; Mingote et al., 2004), together with the baseline NMDA receptor activation, may prevent abnormal LTD induction and secure event-related high-frequency inputs to induce LTP. 


\section{References}

Akil M, Pierri JN, Whitehead RE, Edgar CL, Mohila C, Sampson AR, Lewis DA (1999) Lamina-specific alterations in the dopamine innervation of the prefrontal cortex in schizophrenic subjects. Am J Psychiat 156:1580-1589.

Baldwin AE, Sadeghian K, Kelley AE (2002) Appetitive instrumental learning requires coincident activation of NMDA and dopamine $\mathrm{D}_{1}$ receptors within the medial prefrontal cortex. J Neurosci 22:1063-1071.

Bassareo V, Di Chiara G (1997) Differential influence of associative and nonassociative learning mechanisms on the responsiveness of prefrontal and accumbal dopamine transmission to food stimuli in rats fed ad libitum. J Neurosci 17:851-861.

Brunel N, Wang X-J (2001) Effects of neuromodulation in a cortical network model of object working memory dominated by recurrent inhibition. J Comput Neurosci 11:63-85.

Dias R, Aggleton JP (2000) Effects of selective excitotoxic prefrontal lesions on acquisition of nonmatching- and matching-to-place in the T-maze in the rat: differential involvement of the prelimbic and anterior cingulate cortices in providing behavioural flexibility. Eur $J$ Neurosci 12:4457-4466.

Egerton A, Reid L, McKerchar CE, Morris BJ, Pratt JA (2005) Impairment in perceptual attentional set-shifting following PCP administration: a rodent model of set-shifting deficits in schizophrenia. Psychopharmacol 179:77-84.

Floresco SB, West AR, Ash B, Moore H, Grace AA (2003) Afferent modulation of dopamine neuron firing differentially regulates tonic and phasic dopamine transmission. Nat Neurosci 6:968-973.

Frey U, Matthies H, Reymann KG (1991) The effect of dopaminergic $D_{1}$ receptor blockade during tetanization on the expression of long-term potentiation in the rat CA1 region in vitro. Neurosci Lett 129:111-114.

Fuster JM, Bodner M, Kroger JK (2000) Cross-modal and cross-temporal association in neurons of frontal cortex. Nature 405:347-351.

Goto Y, Grace AA (2005) Dopaminergic modulation of limbic and cortical drive of nucleus accumbens in goal-directed behaviour. Nat Neurosci 8:805-812.

Grace A (1991) Phasic versus tonic dopamine release and the modulation of dopamine system responsivity: a hypothesis for the eiology of schizophrenia. Neuroscience 41:1-24.

Gurden H, Tassin JP, Jay TM (1999) Integrity of the mesocortical dopaminergic system is necessary for complete expression of in vivo hippocampal-prefrontal cortex long-term potentiation. Neuroscience 94:1019-1027.

Herry C, Garcia R (2002) Prefrontal cortex long-term potentiation, but not long-term depression, is associated with the maintenance of extinction of learned fear in mice. J Neurosci 22:577-583.

Hirsch JC, Crepel F (1990) Use-dependent changes in synaptic efficacy in rat prefrontal neurons in vitro. J Physiol (Lond) 427:31-49.

Huang YY, Kandel ER (1995) $D_{1} / D_{5}$ receptor agonists induce a protein synthesis-dependent late potentiation in the CA1 region of the hippocampus. Proc Natl Acad Sci USA 92:2446-2450.

Huang YY, Simpson E, Kellendonk C, Kandel ER (2004) Genetic evidence for the bidirectional modulation of synaptic plasticity in the prefrontal cortex by $\mathrm{D}_{1}$ receptors. Proc Natl Acad Sci USA 101:3236-3241.

Laroche S, Davis S, Jay TM (2000) Plasticity at hippocampal to prefrontal cortex synapses: dual roles in working memory and consolidation. Hippocampus 10:438-446.

Lisman JE, Grace AA (2005) The hippocampal-VTA loop: controlling the entry of information into long-term memory. Neuron 46:1-11.
Miller EK, Cohen JD (2001) An integrative theory of prefrontal cortex function. Annu Rev Neurosci 24:167-202.

Mingote S, de Bruin LPC, Feenstra MGP (2004) Noradrenaline and dopamine efflux in the prefrontal cortex in relation to appetitive classical conditioning. J Neurosci 24:2475-2480.

Mulder AB, Nordquist RE, Ôrgüt O, Pennartz CMA (2003) Learningrelated changes in response patterns of prefrontal neurons during instrumental conditioning. Behav Brain Res 146:77-88.

Otani S (2002) Memory trace in prefrontal cortex: theory for the cognitive switch. Biol Rev Cam Phil Soc 77:563-577.

Otani S, Blond O, Desce J-M, Crepel F (1998) Dopamine facilitates longterm depression of glutamatergic transmission in rat prefrontal cortex. Neuroscience 85:669-676.

Otani S, Auclair N, Desce JM, Roisin M-P, Crépel F (1999) Dopamine receptors and groups I and II mGluRs cooperate for long-term depression induction in rat prefrontal cortex through converging postsynaptic activation of MAP kinases. J Neurosci 19:9788-9802.

Reynolds JN, Hyland BI, Wickens JR (2001) A cellular mechanism of reward related learning. Nature 413:67-70.

Rossi S, Cappa SF, Babiloni C, Pasqualetti P, Miniussi C, Carducci F, Babiloni F, Rossini PM (2001) Prefrontal cortex in long-term memory: an "interference" approach using magnetic stimulation. Nat Neurosci 4:948-952.

Runyan JD, Moore AN, Dash PK (2004) A role for prefrontal cortex in memory storage for trace fear conditioning. J Neurosci 24:1288-1295.

Sajikumar S, Frey JU (2004) Late-associativity, synaptic tagging, and the role of dopamine during LTP and LTD. Neurobiol Learn Mem 82:12-25.

Sawaguchi T, Goldman-Rakic PS (1991) $\mathrm{D}_{1}$ dopamine receptors in prefrontal cortex: involvement in working memory. Science 251:947-950.

Schultz W (1998) Predictive reward signal of dopamine neurons. J Neurophysiol 80:1-27.

Schultz W (2002) Getting formal with dopamine and reward. Neuron 36:241-263.

Seamans JK, Durstewitz D, Christie BR, Stevens CF, Sejnowski TJ (2001) Dopamine $D_{1} / D_{2}$ receptor modulation of excitatory synaptic inputs to layer V prefrontal cortex neurons. Proc Natl Acad Sci USA 98:301-306.

Simon H, Scatton B, Le Moal M (1980) Dopamine A10 neurones are involved in cognitive function. Nature 286:150-151.

Simons JS, Spiers HJ (2003) Prefrontal and medial temporal lobe interactions in long-term memory. Nat Rev Neurosci 4:637-648.

Sokolov BP (1998) Expression of NMDAR1, GluR1, GluR7, and KA1 glutamate receptor mRNAs is decreased in frontal cortex of "neuroleptic-free" schizophrenics: evidence on reversible up-regulation by typical neuroleptics. J Neurochem 71:2454-2464.

Takahata R, Moghaddam B (2000) Target-specific glutamate regulation of dopamine neurons in the ventral tegmental area. J Neurochem 75:1775-1778.

Wang M, Vijayraghavan S, Goldman-Rakic PS (2004) Selective $\mathrm{D}_{2}$ receptor actions on the functional circuitry of working memory. Science 303:853-856.

Williams GV, Goldman-Rakic PS (1995) Modulation of memory fields by dopamine $\mathrm{D}_{1}$ receptors in prefrontal cortex. Nature 376:572-575.

Young CE, Yang CR (2005) Dopamine $\mathrm{D}_{1}$-like receptor modulates layerand frequency-specific short-term synaptic plasticity in rat prefrontal cortical neurons. Eur J Neurosci 21:3310-3320.

Zahrt J, Taylor JR, Mathew RG, Arnsten AF (1997) Supranormal stimulation of $D_{1}$ dopamine receptors in the rodent prefrontal cortex impairs spatial working memory performance. J Neurosci 17:8528-8535.

Zheng P, Zhang XX, Bunney BS, Shi WX (1999) Opposite modulation of cortical $N$-methyl-D-aspartate receptor-mediated responses by low and high concentrations of dopamine. Neuroscience 91:527-535. 